\title{
European Journal of Physical and Rehabilitation Medicine
}

EDIZIONI MINERVA MEDICA

\section{ARTICLE ONLINE FIRST}

This provisional PDF corresponds to the article as it appeared upon acceptance.

A copyedited and fully formatted version will be made available soon. The final version may contain major or minor changes.

\section{Spinal bracing and lung function in type-2 spinal muscular atrophy}

Chiara DI PEDE, Eleonora SALAMON, Matteo MOTTA, Caterina AGOSTO, Franca BENINI, Adriano FERRARI

European Journal of Physical and Rehabilitation Medicine 2018 Apr 24

DOI: 10.23736/S1973-9087.18.05046-3

Article type: Case Report

(C) 2018 EDIZIONI MINERVA MEDICA

Article first published online: April 24, 2018

Manuscript accepted: April 20, 2018

Manuscript revised: April 16, 2018

Manuscript received: October 18, 2017

Subscription: Information about subscribing to Minerva Medica journals is online at: http://www.minervamedica.it/en/how-to-order-journals.php

Reprints and permissions: For information about reprints and permissions send an email to: journals.dept@minervamedica.it - journals2.dept@minervamedica.it - journals6.dept@minervamedica.it 


\title{
Spinal bracing and lung function in type-2 spinal muscular atrophy
}

\author{
Chiara Di Pede ${ }^{1}$, Eleonora Salamon ${ }^{1}$, Matteo Motta ${ }^{2}$, Caterina Agosto ${ }^{1}$, Franca Benini ${ }^{1}$, Adriano \\ Ferrari $^{2 *}$ \\ ${ }^{1}$ Paediatric Pain and Palliative Care Service, Department of Woman and Child Health, University of Padua, Padua, Italy; ${ }^{2}$ Physical and \\ Rehabilitation Medicine, University of Modena and Reggio Emilia, Reggio Emilia, Italy
}

${ }^{*}$ Corresponding author: Adriano Ferrari, UDGEE S. Maria Nuova Hospital, viale Risorgimento 80, 42123 Reggio Emilia, Italy. E-mail: adriano.ferrari@unimore.it

\begin{abstract}
Background: Respiratory muscle weakness associated with scoliosis in type-2 spinal muscular atrophy (SMA) leads to respiratory impairment. Spinal brace, generally utilized to slow scoliosis progression and support sitting, could worsen lung function and hamper cough maneuvers.

Case series: Six home-treated type-2 SMA children (aged 6 -15 years, subtype 2.1-2.5) were assessed to evaluate time-dependent influence of "static-balanced brace" on pulmonary function. Lung function tests, including peak expiratory flow (PEF), peak cough flow (PCF), maximal static inspiratory pressure (MIP), maximal static expiratory pressure (MEP), forced vital capacity (FVC), were performed. PEF, MEP, FVC parameters were higher in tests after wearing braces threehours, PCF slightly higher and MIP slightly lower compared to upon awakening values.

Clinical rehabilitation impact: "Static-balanced brace" did not impair lung function in our sample of type-2 SMA children; in addition, it seemed to support cough maneuvers. Double assessment is determinant for decisions concerning use/non-use of brace.
\end{abstract}

Key words: spinal muscular atrophy, spinal bracing, lung function 


\section{Introduction}

Spinal muscular atrophy (SMA) is caused by deletion of SMN 1 gene, located on chromosome 5, responsible for production of SMN (Survival Motor Neuron) protein. Altered production of this protein leads to degeneration of motor neurons in spinal cord anterior horns, resulting in progressive denervation, muscle atrophy and increasing weakness (1). After cystic fibrosis, SMA is the most common autosomal recessive genetic disease in childhood, with a global incidence of $1 / 10000-1 / 24000$ live births. In general population, its carrier frequency is about 1/40 -1/60.

According to Dubowitz classification (Hammersmith Functional Scale for SMA - HFMS) (2), the scientifically most shared SMA clinical assessment system, patients are divided into four forms depending on onset age, maximal obtainable gross motor function and age at natural exitus (3). All four forms present some variability in clinical manifestations; therefore, in order to obtain maximal patient selection homogeneity for clinical research purposes, SMA forms are further divided into 10 sub-forms. In Type-2 SMA, atrophy begins between six and 18 months; patients are able to maintain sitting position without support, but are unable to stand and walk autonomously. Exitus mainly depends on lung failure. If respiratory supported, most patients can also reach adulthood. Scoliosis greatly contributes to impaired lung function by reducing vital capacity and increasing ventilation/perfusion discrepancy (4).

In neuromuscular disorders (NMD), spinal bracing improves postural control in sitting position and supports upper limb functionality. It has never been demonstrated to slow scoliosis progression (5) and sustain efficaciously lung function.

In literature, few studies have investigated the effects of brace use on lung activity in children with NMD. Noble-Jamieson and colleagues (6) have analyzed consequences of a rigid spinal brace on respiratory function in 16 children affected by NMD (Duchenne Muscular Dystrophy, Congenital Muscular Dystrophy and SMA). Their results showed statistically significant reduction of FVC in pulmonary function tests performed wearing brace. 
Tangsrud and colleagues (7) have analyzed effects of spinal bracing on lung function in five SMA children. Results showed higher average values of tidal flow volume in pulmonary function tests performed without brace, compared to ones wearing brace.

Morillon and colleagues (8) have showed that spinal bracing in children with NMD leads to respiratory impairment, significantly reducing FVC. Their results revealed that the Garchois brace might lead to less severe impairment of respiratory function.

Moreover, to the best of our knowledge, in literature, no studies have fully investigated timedependent effects of bracing on lung function in SMA children.

The aim of this study was to evaluate time-dependent effects of a specific trunk orthosis, the "static-balanced brace", on lung function in a homogeneous group of type-2 SMA children.

\section{CLINICAL SERIES}

Six type-2 SMA children (age 6 - 15 years) with an average age of 116.6 months (range 92-142) were included in this study. Diagnosis was confirmed by extensive evaluation (including clinical, genetic and neurophysiological examinations). In order to compile a homogeneous group, enrolled children were limited to a ranking between $2.1-2.5$ of HFMS scale. In order to clinically quantify functional status, children were assessed, without brace, using 20 out of 33 items of HFMS; in which higher scores ( $\max 40$ ) indicate better abilities (2). HFMS non-evaluated items were inapplicable or inappropriate for our research aims. Our limited case sample is due to low incidence of type-2 SMA children and necessity to assess a homogeneous group for pathology and clinical conditions. For a detailed description of characteristics of the enrolled population, see Table 1.

Lung function evaluation included the following tests: peak expiratory flow (PEF), peak cough flow (PCF), maximal static inspiratory pressure (MIP), maximal static expiratory pressure (MEP), forced vital capacity (FVC) $(9,10)$. PEF and PCF were performed using a mini Wright Peak Flow meter. MIP and MEP were obtained using a portable hand-held Respiratory Pressure Meter (MICRO 
RPM, BioElektron). FVC was measured through a portable hand-held computer-based spirometer (Minispir® New).

Participants wore a "static-balanced" brace daily, as long as they could maintain the sitting position. This is a custom-made univalve trunk orthosis whose plaster cast is taken in sitting position with a neck-cervical traction regulated through a dynamometer at about 1/4 - 1/5 of body weight. Before plaster hardening, traction is removed and child's sitting posture is adapted to obtain the bestbalanced active head position. From the plaster cast, orthotists construct the usual positive plaster model of child's trunk, on which they apply a 3-mm polyethylene sheet, at high temperature, to form the brace structure. An abdominal opening is successively made to permit diaphrag movements. An elastic strip, applied over this opening, aids expiration improving abdominal wall response. An anterior metal sliding mechanism provides brace closure while still allowing lung expansion during inspiration (if "inverted" lung inspiration is not already present). During inspiratory phase, thoracic closure with the anterior sliding mechanism and presence of the large abdominal opening allow child to increase adequately pre-cough volumes.

This brace is termed "static" because it does not require any auto-correction of scoliosis curve, impossible for this type of patient, and "balanced" because it allows total active head control. From our experience, its use is particularly suitable for NMD patients. In Italy, this type of brace has been approved and funded by National Health Service since 1992.

Static balanced brace

In order to assess brace time-dependent effects on lung function, we performed tests without brace upon awakening and after use/non-use of brace for 3 hours. Lung function tests were chronologically carried out under the following conditions during specific sessions on the same day:

1. supine position (without brace) in morning upon awakening;

2. sitting position (without brace) in morning upon awakening;

3. sitting position (without brace) after wearing brace 3 hours; 
4. sitting position (with brace) after wearing brace 3 hours;

5. sitting position (without brace) after 3 hours without wearing brace.

For short periods, muscle fatigue in maintaining sitting position is not appreciable, but becomes critical after a few hours. In fact, in our study, it was impossible to assess lung function on periods longer than three hours without wearing brace due to excessively progressive muscle fatigue related to maintaining sitting position. For each test, the highest value out of three measurements was recorded. All tests were administered by the same researcher (expert physiotherapist). All children were trained to correctly perform assessment maneuvers.

Statistical analysis was performed by Normality test (Shapiro-Wilk) and T-test for paired data. Wilcoxon signed-rank test was used for comparison of paired data. All tests were considered statistically significant for $p<0.05$.

Subject recruitment took place from October 2016 to February 2017 after obtaining informed parental consent. This study was approved by the Ethics Committee of University of Padova.

\section{Discussion}

In literature, only two studies have investigated effects of spinal bracing on FVC in children with $\operatorname{NMD}(6,8)$. In the first one, a significant reduction in FVC during tests performed wearing brace was demonstrated, but the technical characteristics of braces used were not specified. In the second one, children wearing brace showed significantly reduced FVC, even if less severely impaired in subjects wearing Garchois brace.

In order to verify whether wearing braces can affect lung function more than the consequences of muscle fatigue induced by maintaining sitting position without a brace, we performed tests without brace upon awakening and after use/non-use of brace for 3 hours. To the best of our knowledge, in literature there are no studies that have fully investigated time-dependent effects of brace on lung function in children with NMD. 
In five out of the six subjects of our case series, it was possible to perform respiratory function tests. Respiratory test 5 (sitting position without brace after 3 hours without wearing brace) was not performed in subject number 4 because of excessive trunk muscle weakness that inhibited a prolonged sitting position without brace. Anyhow, in this patient, prolonged brace use did not reduce parameters measured in sitting position upon awakening, except for MIP. This data confirms the previous statement concerning the choice of suitable test period. In tests performed upon awakening, before wearing brace, PEF, PCF, MIP and MEP mean and median values were higher in sitting position. Only PCF was statistically significant $(p=0.05)$. FVC values were roughly equivalent, confirming diaphragm muscle preservation in type-2 SMA children.

After three hours of brace use, mean and median values of parameters were overall better in tests performed wearing brace. PEF, PCF and MEP values were significantly higher. MIP was lower. No statistically significant differences were found in values of all parameters.

In tables 2 and 3 all test mean and median values with standard deviation.

Collected data of our six-enrolled type-2 SMA children showed that lung function was not adversely affected by wearing the static-balanced brace. In fact, we found that cough effectiveness measures (PEF, PCF and MEP) and particularly PCF and MEP were better in tests performed in sitting position with brace, whereas FVC was not modified. Improvement of cough effectiveness parameters in tests performed with static balanced brace can be attributed to specific technical characteristics of this orthosis that support the first and last cough phases.

Analysis of results of this study revealed no statistically significant differences, except in MIP value, which was slightly reduced in tests performed after wearing brace for 3 hours compared to values observed upon awakening. As the MIP value is an expression of strength of inspiratory muscles, its small reduction in tests performed after wearing brace for 3 hours could be interpreted as gradual diaphragm fatigue due to increased effort imposed by orthoses constraint. Parameter analysis of cough effectiveness did not show any significant changes. This assessment is determinant for 
decisions concerning use/non-use of brace, differently from the usual one-time evaluation (base level compared to level wearing brace).

\section{Conclusions}

Preliminary findings from this study suggest that in type-2 SMA children:

- lung function is better in sitting position than in supine one,

- static-balanced brace can support cough maneuvers,

- static-balanced brace does not impair lung function in terms of FVC,

- prolonged use of static-balanced brace can reduce MIP,

- diaphragm muscle is less compromised, but fatigue has to be constantly monitored because brace, constraining thorax, reduces its expansion.

Regular assessment of pulmonary function, including parameters of respiratory muscle strength, is imperative.

Our limited case sample does not allow us to extend study conclusions to general population of type-2 SMA children. However, our standardized and reliable procedure can allow testing of other homogeneous groups of NMD and other types of trunk orthoses.

We would like to thank our patients their families and members of Pediatric Palliative Care team.

\section{References}

1. Aicardi J, Bax M, Gillberg C. Diseases of the Nervous System in Childhood. Third Edition.

Clinics in Developmental Medicine N²52, March 2009.

2. Dubowitz V. Chaos in the classification of SMA: a possible resolution. Neuromuscul Disord 1995 $\operatorname{Jan} ; 5(1): 3-5$.

3. Wang $\mathrm{CH}$, Finkel RS, Bertini ES, Schroth $\mathrm{M}$, Simonds A, Wong B and Participants of the International Conference on SMA Standard of Care. Consensus statement for standard of care in spinal muscular atrophy. J Child Neurol 2007 Aug; 22(8):1027-49. 
4. Chng SY, Wong YQ, Hui JH, Wong HK, Ong HT, Goh DY. Pulmonary function and scoliosis in children with SMA types II and III. J Paediatr Child Health 2003 Dec;39(9):673-6.

5. Merlini L, Granata C, Bonfiglioli S, Marini ML, Cervellati S, Savini R. Scoliosis in spinal muscular atrophy: natural history and management. Dev Med Child Neurol 1989 Aug;31(4):501-8.

6. Noble-Jamieson CM, Heckmatt JZ, Dubowitz V, Silverman M. Effects of posture and spinal bracing on respiratory function in neuromuscular disease. Arch Dis Child 1986 Feb;61(2):178-81.

7. Tangsrud SE, Carlsen KC, Lund-Petersen I, Carlsen KH. Lung function measurements in young children with spinal muscle atrophy; a cross sectional survey on the effect of position and bracing. Arch Dis Child 2001 Jun;84(6):521-4.

8. Morillon S, Thumerelle C, Cuisset JM, Santos C, Matran R, Deschildre A. Effect of thoracic bracing on lung function in children with neuromuscular disease. Ann Readapt Med Phys 2007 Nov;50(8):645-50.

9. Fauroux B, Khirani S. Neuromuscular disease and respiratory physiology in children: putting lung function into perspective. Respirology 2014 Aug;19(6):782-91.

10. Sansone VA, Racca F, Ottonello G, Vianello A, Berardinelli A, Crescimanno G, et al. Italian SMA Family Association. First Italian SMA Family Association Consensus Meeting: Management and recommendations for respiratory involvement in spinal muscular atrophy (SMA) type I-III

\section{Notes}

All authors contributed equally to the manuscript.

Chiara Di Pede, Paediatric Pain and Palliative Care Service, Department of Women's and Children's Health, University of Padova.

Eleonora Salamon, Paediatric Pain and Palliative Care Service, Department of Women's and Children's Health, University of Padova.

Matteo Motta, Master of child rehabilitation, Physical and Rehabilitation Medicine, University of Modena and Reggio Emilia.

Caterina Agosto, Paediatric Pain and Palliative Care Service, Department of Women's and Children's Health, University of Padova.

Franca Benini, Paediatric Pain and Palliative Care Service, Department of Women's and Children's Health, University of Padova.

Adriano Ferrari, Physical and Rehabilitation Medicine, University of Modena and Reggio Emilia. 
Table 1. Description of enrolled SMA children.

\begin{tabular}{|l|l|l|l|l|l|l|l|l|}
\hline Subject & Sex & $\begin{array}{l}\text { Age } \\
(\mathrm{mth})\end{array}$ & $\begin{array}{l}\text { SMA } \\
\text { Type }\end{array}$ & $\begin{array}{l}\text { Weight } \\
(\mathrm{kg})\end{array}$ & $\begin{array}{l}\text { Arm } \\
\text { Span } \\
(\mathrm{cm})\end{array}$ & Scoliosis (Cobb's angle) & $\begin{array}{l}\text { Nocturnal non } \\
\text { invasive } \\
\text { ventilation }\end{array}$ & HFMS \\
\hline 1 & $\mathrm{M}$ & 130 & 2.2 & 38,5 & 135 & Right dorso-lumbar $\left(31^{\circ}\right)$ & yes & $9 / 40$ \\
\hline 2 & $\mathrm{M}$ & 119 & 2.1 & 50 & 142 & Right dorso-lumbar (46 $)$ & no & $6 / 40$ \\
\hline 3 & $\mathrm{~F}$ & 92 & 2.5 & 40 & 130 & Left dorso-lumbar $\left(38^{\circ}\right)$ & no & $26 / 40$ \\
\hline 4 & $\mathrm{~F}$ & 102 & 2.3 & 25 & 120 & Right dorso-lumbar $\left(45^{\circ}\right)$ & yes & $7 / 40$ \\
\hline 5 & $\mathrm{M}$ & 142 & 2.3 & 41 & 146 & Left dorsal (28 $)$ & no & $15 / 40$ \\
\hline 6 & $\mathrm{~F}$ & 115 & 2.3 & 23 & 121 & Right dorso-lumbar $\left(9^{\circ}\right)$ & no & $17 / 40$ \\
\hline
\end{tabular}


Table 2. Effects of sitting position on lung function

\begin{tabular}{|c|c|c|c|c|c|c|c|c|c|}
\hline \multirow{3}{*}{ Variable } & \multicolumn{6}{|c|}{ Status } & \multirow{3}{*}{$\begin{array}{l}\text { Normality } \\
\text { test } \\
\text { (Shapiro- } \\
\text { Wilk) } \\
\\
\text { p-value }\end{array}$} & \multirow{3}{*}{$\begin{array}{l}\text { T test for } \\
\text { paired } \\
\text { data }\end{array}$} & \multirow{3}{*}{$\begin{array}{l}\text { Wilcoxon } \\
\text { test for } \\
\text { paired } \\
\text { data }\end{array}$} \\
\hline & \multicolumn{3}{|c|}{ Sitting position upon awakening } & \multicolumn{3}{|c|}{ Supine position upon awakening } & & & \\
\hline & Mean & Median & Std Dev & Mean & Median & Std Dev & & & \\
\hline PEF & 181.00 & 180.00 & 22.47 & 175.00 & 165.00 & 37.42 & 0.4931 & 0.6633 & 0.8551 \\
\hline PCF & 192.00 & 200.00 & 36.33 & 155.00 & 150.00 & 29.15 & 0.0179 & 0.0098 & 0.0545 \\
\hline MIP & 62.80 & 63.00 & 5.72 & 57.80 & 58.00 & 3.19 & 0.4168 & 0.2045 & 0.1875 \\
\hline MEP & 42.60 & 40.00 & 7.02 & 37.20 & 39.00 & 3.96 & 0.5986 & 0.1192 & 0.1250 \\
\hline FVC & 1.64 & 1.40 & 0.46 & 1.64 & 1.42 & 0.44 & 0.9150 & 1.0000 & 1.0000 \\
\hline
\end{tabular}


Table 3. Effect of brace on lung function

\begin{tabular}{|c|c|c|c|c|c|c|c|c|c|}
\hline \multirow{3}{*}{ Variable } & \multicolumn{6}{|c|}{ Status } & $\begin{array}{l}\text { Normality } \\
\text { test } \\
\text { (Shapiro- }\end{array}$ & $\begin{array}{l}T \text { test for } \\
\text { paired } \\
\text { data }\end{array}$ & $\begin{array}{l}\text { Wilcoxon } \\
\text { test for } \\
\text { paired }\end{array}$ \\
\hline & \multicolumn{3}{|c|}{ Sitting position upon awakening } & \multicolumn{3}{|c|}{$\begin{array}{l}\text { Sitting position with brace sitting } \\
\text { position (with brace) after wearing } \\
\text { brace } 3 \text { hours }\end{array}$} & \multirow[t]{2}{*}{$p$-value } & \multirow[t]{2}{*}{$p$-value } & \multirow[t]{2}{*}{$\begin{array}{l}\text { Exact } \\
\text { p--value }\end{array}$} \\
\hline & Mean & Median & Std Dev & Mean & Median & Std Dev & & & \\
\hline PEF & 181.00 & 180.00 & 22.47 & 210.00 & 205.00 & 35.18 & 0.0817 & 0.1456 & 0.3125 \\
\hline PCF & 192.00 & 200.00 & 36.33 & 210.00 & 200.00 & 29.15 & 0.2230 & 0.1045 & 0.0975 \\
\hline MIP & 62.80 & 63.00 & 5.72 & 61.00 & 57.00 & 8.46 & 0.1072 & 0.4103 & 0.5807 \\
\hline MEP & 42.60 & 40.00 & 7.02 & 52.80 & 51.00 & 8.04 & 0.5986 & 0.0646 & 0.1250 \\
\hline FVC & 1.64 & 1.40 & 0.46 & 1.64 & 1.36 & 0.44 & 0.9128 & 0.9427 & 0.8923 \\
\hline
\end{tabular}




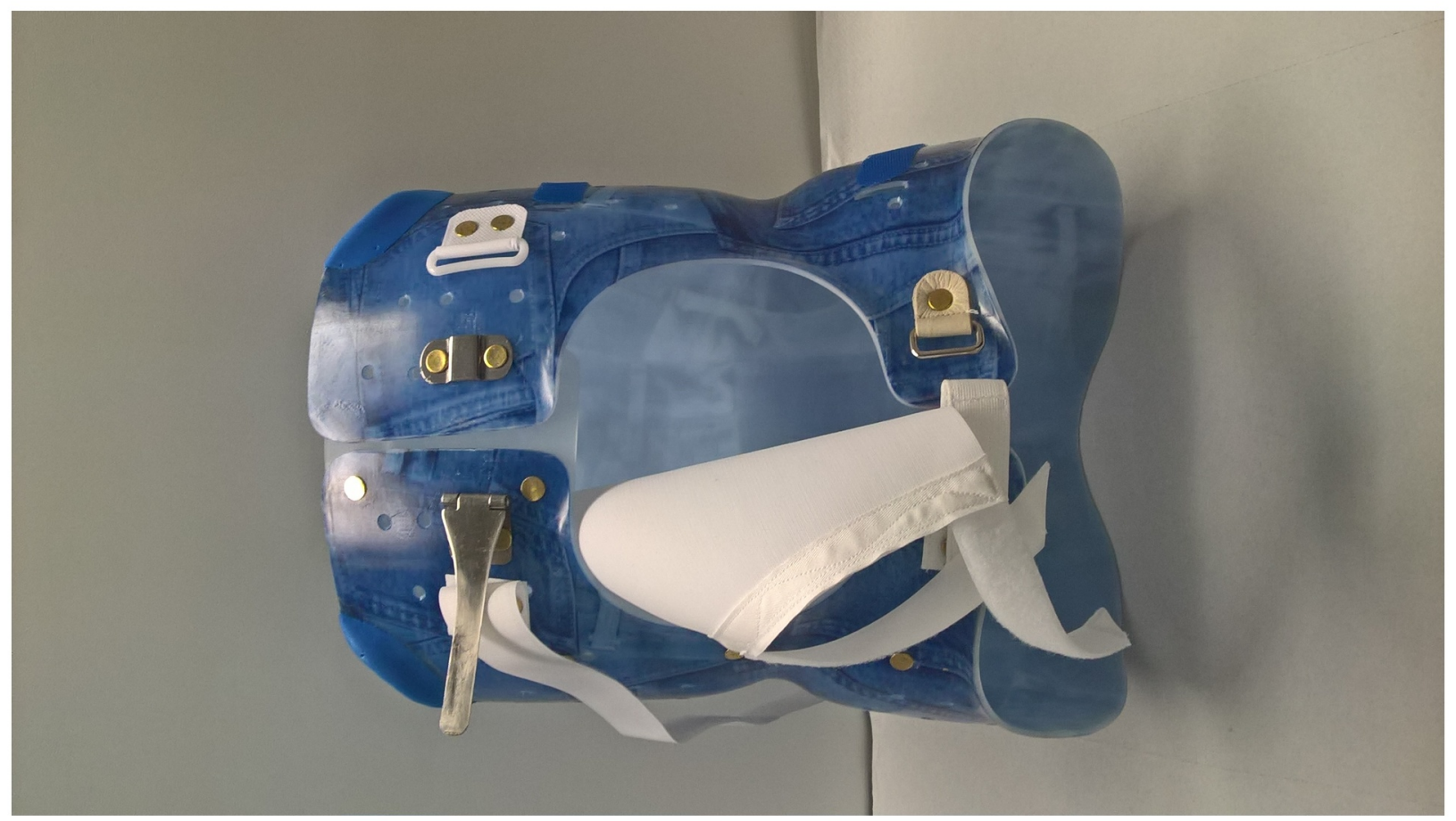

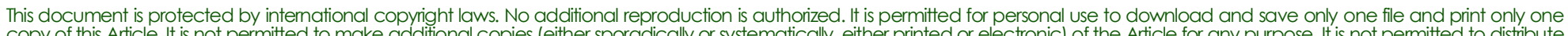

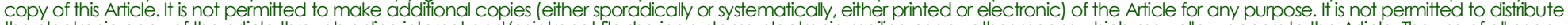

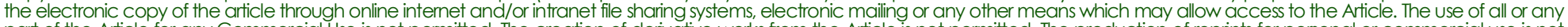

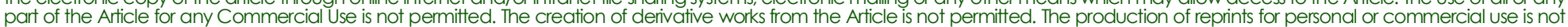

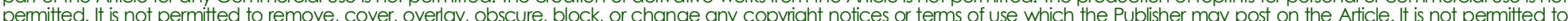
frame 